\title{
The Development of the new ING.PAED.IGIP Curriculum into an Umbrella for Modularised National and Regional Engineering Education Curricula
}

\author{
http://dx.doi.org/10.3991/ijep.v4i1.3244 \\ Dr. Axel Zafoschnig \\ IGIP Executive Committee and Austrian Ministry of Education, Austria
}

\begin{abstract}
IGIP has been the sole provider of an internationally renowned and acknowledged curriculum for engineering education and pedagogy over the past 40 years. More than 2000 engineering educators and technical teachers at different institutional levels in many countries have successfully received their pedagogical and didactic training through this curriculum Today new legal requirements and IGIP's awareness-raising campaign in many states have led to the implementation of a lot of compulsory teacher training programmes in this field. IGIP has, however, always been able to stay on top of these developments and has now come up with its new 2013 Berlin version of the ING-PAED IGIP curriculum. The results and findings of the international curriculum task force are now available and have been finalised and approved by the Executive Committee. How the task force has worked and which models of modularised engineering education curricula they have also analysed and compared in this process will be shown in this paper.
\end{abstract}

Index Terms-ING-PAED IGIP, curriculum development, modularised curriculum, core modules, teacher training, engineering education, VET.

Curriculum development in engineering pedagogy or engineering education is inseparably linked with names like Adolf Melezinek, the Dresden School of Engineering Pedagogy, or with the term INF-PAED IGIP diploma. For more than 10 years now, a well-working version of the curriculum has served as the basis for the training and the pedagogical education of technical teachers at technical colleges and universities all over the world. More than 2000 colleagues in more than 30 countries have in the meantime acquired this universally acknowledged title of ING-PAED IGIP, the IGIP International Engineering Educator.

Since the year 2008 it has, however, been the merit of IGIP President Michael Auer to determinedly lead IGIP into a new phase of curriculum development. After numerous meetings and long discussions during which a consensus among the individual and institutional IGIP members could not be expected to be achieved easily, he finally managed to reach a break-through with the idea to create an efficient task force consisting of curriculum experts from almost 10 countries to deal with the matter in a target-oriented way.
Highly experienced and esteemed colleagues like Dana Dobrovska, Pavel Andres, Teresa Restivo, Tia Rüütmann, Jose Marques, Roman Hrmo, Melany Ciampi, Claudio da Rocha Brito, Danilo Garbi Zutin, Alexander Soloviev, Ralph Dreher and Axel Zafoschnig made intensive and comprehensive preparations for this ambitious project. At the EDUCON Conference in Berlin they pooled their experiences, shared available information and re-launched the ING-PAED IGIP curriculum in such a way that it would meet with the requirements of modern institutions offering engineering pedagogy programmes for the technical teachers trained in their various countries.

The overall objective had always been to come up with a flexible, dynamic and effective curriculum in which as many technical institutions as possible would find themselves and which would serve as a kind of umbrella for national and regional engineering education curricula. In addition, the demand for technical teacher training in the form of modularised and ready-made training programmes has increasingly become a requirement expressed by many academic institutions, in particular by technical universities.

IGIP has also been contacted by various engineering societies and associations from all over the world to allow their ING-PAED IGIP curriculum to be utilised in engineering education as a kind of franchised framework that could be adapted to national and institutional needs. IEEE (the Institute of Electrical and Electronics Engineers) for example, the world's largest professional association dedicated to advancing technological innovation and excellence for the benefit of humanity, has explicitly expressed a genuine interest in the new curriculum, because it has, in spite of its excellent achievements in promoting the development and delivery of continuing education materials in the field of technology, so far not produced an engineering education curriculum of its own as an essential component alongside its educational activities.

At the same time, LACCEI (the Latin American and Caribbean Consortium of Engineering Institutions), the leading organisation of Latin American and Caribbean engineering institutions that offer academic programs in Engineering and Technology, has demonstrated a serious interest in setting up an IGIP Training Centre in its sphere of influence so as to be able to offer new initiatives in the field of engineering education and to increase engineering program accreditation in the Americas. 
Further requests in this direction have come from India and China, also from IFEES (the International Federation of Engineering Education Societies) but most of all from SEFI, one of the largest networks of engineering education institutions and educators in Europe. SEFI's aims and objectives are to contribute to the development and to the improvement of engineering education in Europe and across the world. It has, however, not planned any curriculum activities that would result in the design of its own engineering education curriculum for individuals and the latters' accreditation. In this matter, IGIP President Michael Auer and SEFI President Claudio Borri have met and decided to increase the mutual co-operation between the two sister societies in this field.

Apart from all these requests from others, another vision for the new ING-PAED IGIP curriculum is to create online modules for which different renowned academic institutions would take over responsibility, i.e. one module could be designed and offered by a European university, others by US or Russian engineering education specialists. Such partners could for example be found at befriended universities of technology like MIT in Boston, TU Dresden, MADI Moscow, and others.

Coming back to the meeting of the task-force that met in Berlin in March 2013, it was the main objective of the curriculum experts to provide an update of the ING-PAED IGIP curriculum so as to support the outreaching activities of IGIP and other engineering education societies for the sake of being able to award an adapted and modern INGPAED IGIP certificate to individual engineering educators. The pragmatic aim was also to come up with a result in the form of an updated and new curriculum that would help to overcome the differences in national and regional engineering education specifications.

The task force expressed a clear commitment to provide an umbrella or prototype curriculum which could then be approved by the Executive Committee of IGIP and could be applied by the National Monitoring Committees, as well as by other licenced academic institutions or training centres. The task-force also soon came to the conclusion that the existing curriculum should be further developed, adapted and modernised, as far as content and structure are concerned. It soon also became clear that a modularised curriculum with core modules, as well as with theoretical, practical and elective modules, would serve as the best basis for special courses or programs in engineering education.

Some guidelines that also became apparent in the process of developing the new curriculum were that the INGPAED IGIP identity and also the structure should be retained, that modern trends and tendencies in engineering education should be included, and that most of all, a combination of theory and practice should be offered for teachers of engineering through the provisions of the new curriculum.

The task force found it useful to kick off with a survey of the history and the chronology of the ING-PAED IGIP curriculum in order to be able to start from a common denominator. At the same time, it became obvious in the course of the discussion that the academic degree of a bachelor should be the minimum requirement for an INGPAED IGIP. Other aspects that were also mentioned and considered to be important were the international marketability of the ING-PAED IGIP certificate, the focussing on a modular structure that should contain anything between 4 and 14 modules, and the threshold level of $20 \mathrm{CPs}$ that would guarantee flexibility and professionalism at the same time.

For the curriculum design process it was important to get an overview of existing modularised national and regional engineering education curricula so as to be able to compare those with the content and the structure of the ING-PAED IGIP curriculum and in order to decide how methodology, didactics and pedagogy could be integrated into the curriculum, together with the relevant content.

In a first phase the task force looked at the old INGPAED IGIP curriculum [1] that was basically organised in 6 modules and represented a workload of approximately 20 ECTS.

Based on the old Melezinek model, the traditional INGPAED IGIP engineering pedagogy curriculum had the fundamental modules of engineering pedagogy in theory and practice in the middle of the three-column structure, and the theory modules psychology and sociology, ethics and intercultural competencies constituted the left column, whereas the practice modules of rhetoric, communication, scientific writing, along with working with projects, the media, e-learning and computer aided technologies formed the right column. Underneath the fundamental modules were the basic modules of laboratory didactics as well as a comprehensive approach towards portfolio and examination work. Together with a profile of the graduate students and an inventory of their objectives, a sound overall picture of their professional, general, specific knowledge and skills would form the foundation for their registration as ING-PAED IGIP.

In order to provide some materials for comparison, Axel Zafoschnig as the moderator showed the group the $\mathrm{PH}$ Kärnten modularised curriculum for the certified engineering educator program that was mainly aimed at technical teachers at VET colleges (classroom and laboratory) [2] and offers 18 ECTS in four semesters and with four modules.

As said above, this 4-module course lasts four semesters and requires a workload of 13 weekly hours per semester. The four areas in which the prospective engineering teachers get their specific training are the humanities, special technical disciplines and didactics of the technical subjects, as well as practical experience in teaching at school, and additional studies. Those university graduates who want to become certified engineering educators (and thus also receive the ING-PAED IGIP award) must attend the following courses in each of the four modules:

1. Introduction to teaching (organisation of institution, planning of lessons, administration, legal information), basics of engineering pedagogy

2. Social competence (professional, vocational, pedagogical information), teaching styles, types, forms of teaching (problem-based, project-based, blended learning), learning and teaching psychology and communication

3. Engineering education / pedagogy (vocational) work with curricula, extract information and plan a year's teaching, structuring and dividing of content, formulation of competences

4. Teaching practice and analysis, self- and external evaluation, reflexion, quality management and control (plan, act, check, do) 


\author{
Additional activities: Teaching at school / Portfolio \\ work
}

Of course, all these modules consider the aspect of lifelong learning and guarantee that the students increase their professional, subject-specific and methodological competencies in engineering education.

After taking a look at a short-cycle course in engineering education, PH Kärnten's long-cycle training programme for the certified engineering educators in the VET College workshops [3] was introduced. This includes a six-semester academic programme which is completed with the academic degree of a Bachelor of Education and has a workload of $60+120$ ECTS.

This study course is based on the curriculum that through its final examination - enables the prospective engineering teachers who initially started out as masters in a special trade (locksmiths, plumbers, bricklayers, mechanics, computer technicians, etc.) to teach as qualified teachers in the workshops and laboratories of the Austrian technical schools and colleges at secondary level (14-19 year olds). Within the three years in which the modules must be taken, the prospective teachers spend the first and the third year at the PH Kärnten so that they can teach and school and attend courses at the same time. In the second year they are at the PH Steiermark as full-time students. In all six semesters, the following six teaching modules must be completed and exams in each of the following content points must be taken:

1. Introduction to Engineering Pedagogy

- Teaching practice I

- Basics of humanities I (psychology, sociology, educational science, etc.)

- Introduction to specific areas of engineering sciences I

2. Basics of humanities II

- Project management

- Basics of scientific working

- Introduction to specific areas of engineering sciences II

3. Media and methods in teaching at Technical College

- Young people in the world of work

- Personality development of youths

- Teacher development and professionalisation

- Introduction to specific areas of engineering sciences III

4. Grading and assessment, evaluation of student performance

- Social and global aspects of engineering pedagogy

- Personality development within one's job

- Special aspects of VET

- Introduction to specific areas of engineering sciences IV

5. Heterogeneity of learners and alternative forms of teaching

- Blended learning

- Intercultural pedagogy, inclusion

- Writing of the bachelor thesis

- Introduction to specific areas of engineering sciences $\mathrm{V}$
6. Learning techniques and

- Social learning

- Crisis management

- School development

- Adult education (mature students)

- Project-based teaching

- Writing of the bachelor thesis

- Introduction to specific areas of engineering sciences IV

Another interesting contribution came from the Technical University Dresden (Technische Universität Dresden) which sent its study program for engineering didactics (Ingenieurdidaktik) [4] consisting of four modules to IGIP for inspection and evaluation. The Dresden curriculum which was designed under the supervision of Hanno Hortsch takes into consideration that an engineering education course must consist of a combination of theoretical and practical modules, an approach which is unanimously shared by all IGIP experts. Hereby, the prospective teachers should complete the following four modules online and with an attendance phase:

1. Basics of Engineering Didactics

- Characteristic features of teaching and learning processes

- Didactic media for teaching engineering

- Communication and communicative processes

- Grading and assessment of performance

2. Academic Teaching and Learning

- Lectures/seminars/workshops, etc.

- Consultation

- Laboratory practice

- Planning of engineering practice workshops

3. Setting of objectives and of teaching content

- Course design

- Content design

4. Teaching practice and case studies

- Reflexion and evaluation of teaching processes

- Feedback from colleagues participants, observers

- Exam: Live lesson including planning, delivery and evaluation

Ralph Dreher from the Bergische Universität Wuppertal also provided some input by describing his University's focus on engineering education [5] which is mainly characterised by emphasising the importance of project-based assessment. This approach starts with basics and leads from the designing of one lecture to working with comprehensive projects:

1. Designing of a lecture

2. Planning of a whole lecture

3. Planning and designing of seminars

4. Working with a research/exam/colloquium frame

5. Designing of exercises/workshops/tasks

6. Working in the laboratory

7. Working with projects

Other aspects that were mentioned by Ralph Dreher were that the teaching should progress from simple to complex matters and that the bachelor study courses in engineering must offer engineering competence on the one 
hand and soft skills or social skills on the other hand. With regard to reflexion and evaluation, the two main components should be self-reflexion and external evaluation.

With regard to competence orientation, the new curricula for the Austrian Technical Colleges that were developed by the Austrian Ministry of Education was then introduced in Berlin. This curriculum focuses on learning outcomes and prototypical examples, as well as on educational and occupational standards which are to be put into realization by the VET colleges.

The description of the education standards that have been implemented in the VET colleges in Austria is essentially based on the taxonomy of learning that consists of 6 levels and was developed by Benjamin Bloom at the University of Chicago (1956) and then developed further by Anderson and Kratwohl (2001) by means of a table that defines and describes the learning processes in dimensions [6].

Based on the above-mentioned descriptions, Austria has developed its own model which is depicted in Figure 1

With the help of this module, each core competence that is achieved within an education can also be described and illustrated by learning outcomes that are determined by concrete and cognitive parameters. This system allows teachers and learners, but also tertiary education institutions and prospective employers alike, to see immediately and transparently which competences can be expected from the VET college graduates in Austria. The stakeholders of the Austrian VET colleges have agreed to apply this system of educational and occupational standards to all their curricula and VET programs, which means that also the technical teachers must have an acknowledged engineering education qualification.

At the Berlin meeting of the task force, another proposal came from the Portuguese delegation that also provided a module of a curriculum that has partly already been put into consideration by the University of Porto. An interesting aspect of this curriculum is that it tries to stay close to the identity and the structure of the existing ING-PAED IGIP curriculum, but that it also introduces new tools (like critical thinking or infoliteracy) and provides a possible solution for considering both the classic and the flexible as well as the adaptive necessities of curriculum design. What it also provides - apart from the integration of new developments and innovations - is a "Final project", and thus the possibility to not only award the students with a university certificate, but also with the ING-PAED IGIP certificate at the same time. [7]

According to the requirements of the University of Porto, the core modules, the theory modules, and the practice modules are nearly the same as in the IGIP structure, however, what is new is their module 14, which is the "Final project"- module. The Portuguese module also puts a lot of emphasises on their module 7 "Thinking skills and creativity".

After the intense presentations and discussions related to the above-mentioned curriculum models, it became apparent that a new adapted and modernised ING-PAED IGIP curriculum would have to be the result for further successful work in engineering education. Therefore, the expert panel reached a logical conclusion and suggested the following procedure.

From the present state of the curriculum, the task force would start working on the new module descriptions under the leadership of Pavel Andres. Here it became apparent that there is no need to change the curriculum structure, but to take a thorough look at the teachers' profiles and competences, to consider the aspects of training and retraining, as well as of problem-based learning and assessment. A thorough reflexion process was also considered to be a main part of engineering education. But it was also agreed that a proposal for any new modularised curriculum would be submitted to the IGIP Executive Committee and that the descriptions of the various modules would also be worked on, revised and added.

In Table I you can already find this new ING-PAED IGIP engineering education/pedagogy curriculum with its altogether seven basic modules and eight elective modules. From the feedback within the task force and from further comments that came from engineering education societies and experts from all over the world, this new

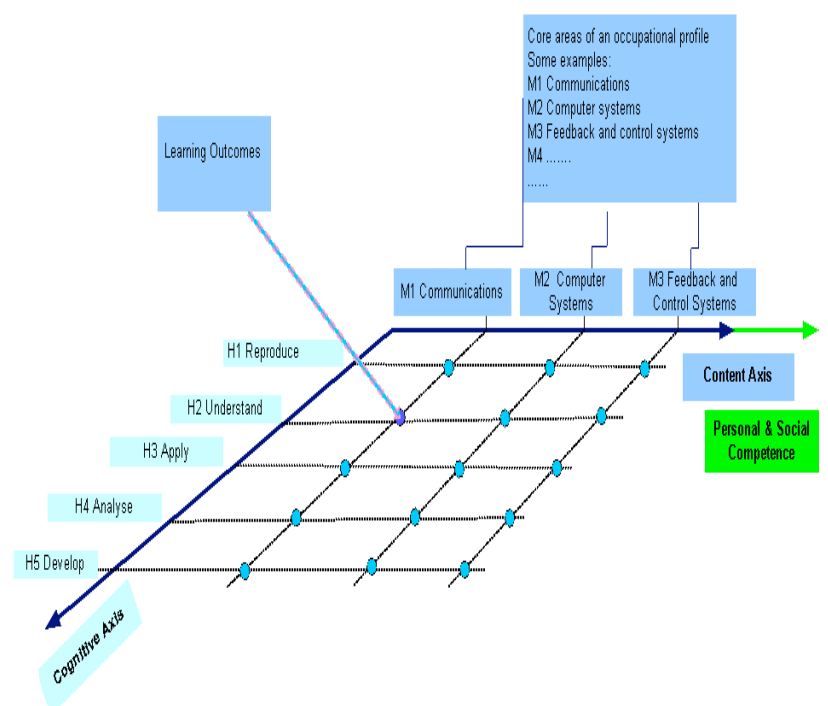

Figure 1.

TABLE I.

\begin{tabular}{|c|c|c|}
\hline & $\begin{array}{c}\text { New ING-PAED IGIP Engineering } \\
\text { Education / Pedagogy Curriculum }\end{array}$ & $\begin{array}{c}\text { CPs at } \\
\text { least }\end{array}$ \\
\hline & Totally & $\mathbf{2 0}$ \\
\hline M1 & Core Modules & $\mathbf{7}$ \\
\hline M2 & Engineering Education in Theory & 2 \\
\hline M3 & Laboratory Didactics & 3 \\
\hline & Theory Modules & 2 \\
\hline M4 & Psychology & $\mathbf{5}$ \\
\hline M5 & Sociology & 2 \\
\hline M6 & Engineering Ethics & 1 \\
\hline M7 & Intercultural Competence & 1 \\
\hline & Practice Modules & 1 \\
\hline M4 & Presentation and Communication Skills & $\mathbf{5}$ \\
\hline M5 & Scientific Writing & 2 \\
\hline M6 & Working with Projects & 1 \\
\hline M7 & ICT in Engineering Education & 1 \\
\hline & Elective Modules (1 CP per subject) & 1 \\
\hline ECP8 & Evaluation of student performance & $\mathbf{3}$ \\
\hline ECP9 & Quality Management & 1 \\
\hline ECP10 & Portfolio Assessment & 1 \\
\hline ECP11 & Creative Thinking & 1 \\
\hline ECP12 & Coaching and Mentoring in Education & 1 \\
\hline ECP13 & Collaborative work & 1 \\
\hline ECP15 & Teaching Subject in English (CLIL) & 1 \\
\hline ECP16 & Infoliteracy & 1 \\
\hline & & \\
\hline
\end{tabular}


curriculum represents a great accomplishment and a genuine improvement of the recent curriculum-development work over previous attempts. The increased interest from many stakeholders involved in engineering education shows that the development of the new ING-PAED IGIP curriculum into an umbrella for modularised national and regional engineering education curricula has set a milestone in this field, because it helps to combines individual efforts in one common project. It can, however, also be used for new engineering teachers on the one hand and for experienced teachers on the other hand, since it has this practical modularised structure which enables teaching institutions either to use the full package or only certain required modules. In any case, it may finally be stated that the new ING-PAED IGIP curriculum can serve as a basis for short-cycle or long-cycle engineering education programmes all over the world [8].

\section{REFERENCES}

[1] http://igip.org/igip/documents/diploma_recomendations.pdf

[2] "Lehrgang zertifizierter/e Ing. Pädago-ge/Pädagogin", Pädagogische Hochschule Kärnten, Viktor Frankl Hochschule, Curriculum vom 28. Februar 2012 pp. 1 - 22
[3] Curriculum für das „Lehramt für den technisch-gewerblichen Fachbereich an berufsbildenden mittleren und höheren Schulen“, Verordnung der Studienkommis-sion der Pädagogischen Hochschule Kärnten vom 05. Juli 2007, pp 1 - 49

[4] Projekt „Ingenieurdidaktik an sächsischen Hoch-schulen „eDidakt", ed. Marcel Köhler, Timon Umlauft, Steffen Kersten, Hartmut Simmert, Technische Universität Dresden, Fakultät Erziehungswissenschaften, Institut für Berufspädagogik, pp 1- 203

[5] „The possibility of a PBA-oriented curriculum in engineering education", Ralf Dreher, Moskau, 16. März 2012 pp 1 - 18

[6] Anderson L. and Kratwohl D., in „A Taxonomy of Learning, Teaching and Assessing", 2001

[7] Theresa Restivo, Jose Marques, University of Porto, "Presentation of the UoP Curriculum”, Berlin 13th March, 2013

[8] New ING-PAED IGIP engineering educa-tion/pedagogy curriculum, IGIP task force, Berlin 2013

\section{AUTHOR}

LSI HR Prof. Mag. Dr. Axel Zafoschnig, ING.PAED.IGIP is with the IGIP Executive Committee, and VET Chief Inspector for Carinthia, Austrian Ministry of Education (axel.zafoschnig@1sr-ktn.gv.at).

Submitted 11 October 2013. Published as re-submitted by the author 23 January 2014. 